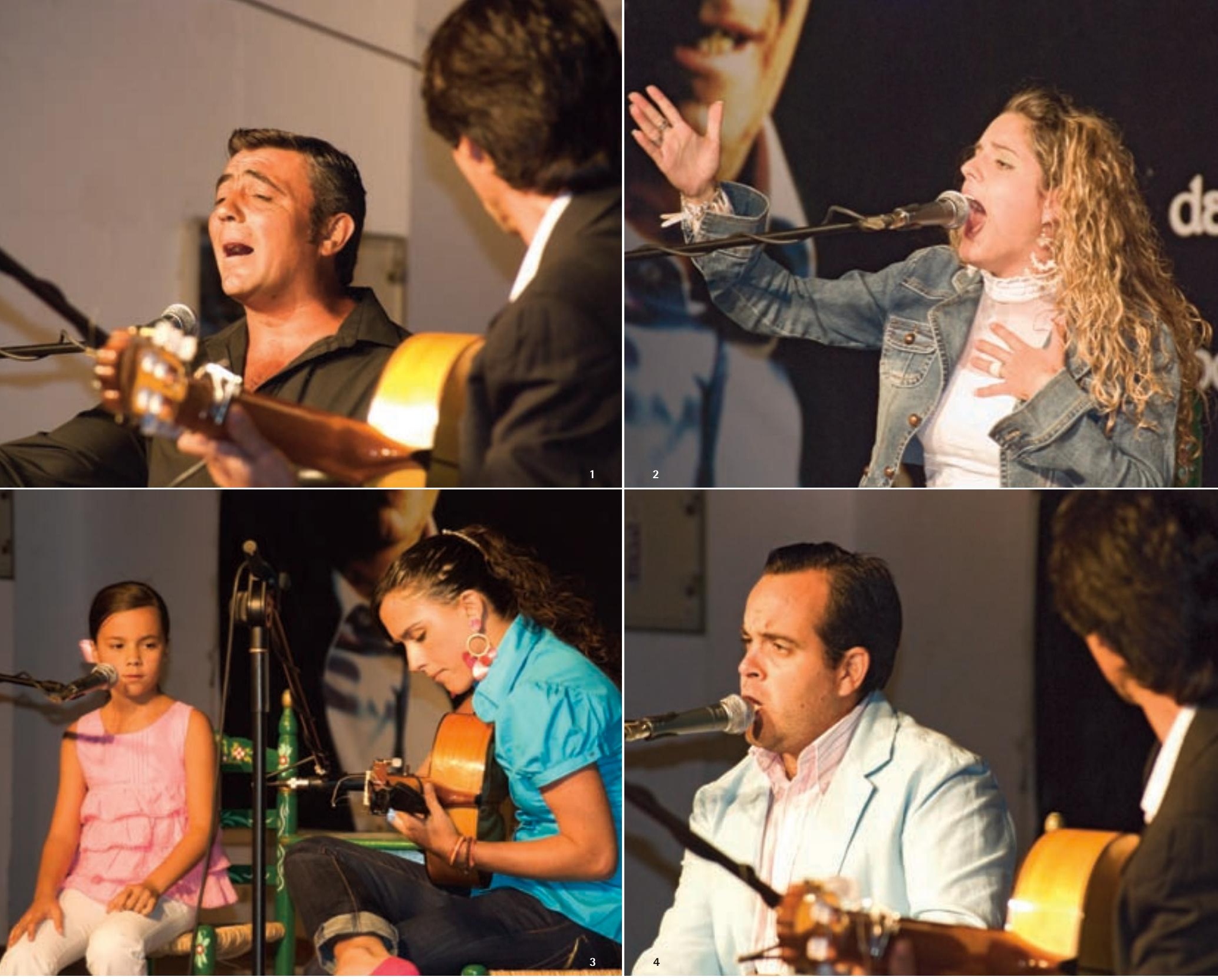

Certamen Nacional de Fandango "Paco Toronjo" (Alosno). Fotos: Aniceto Delgado Méndez, IAPH

\title{
El fandango en Alosno
}

Habrá pocos pueblos en la geografía española tan ligados a un tipo determinado de música como Alosno lo ha estado desde siempre al fandango. En innumerables ocasiones he oido fuera de nuestros limites la expresión: -"¿eres de Alosno?, jentonces cantarás fandangos!", como si el mero hecho de nacer en esta localidad otorgara la facultad de dominar esta modalidad musical.

$Y$ bien es verdad que aunque este sea un tipo de cante común por otras localidades de la provincia onubense, en Alosno se ha vivido desde siempre de una manera especial el mundo del fandango. Es rara la casa en la que aún no se conserve como oro en paño una colección manuscrita con cientos de letras, recopiladas a través de años por alguno de los componentes de la familia, normalmente una mujer, y en las que se recoge en cada uno de sus cinco versos todo sobre lo humano y lo divino, sobre el amor y el desamor, sobre la mina y el campo, sobre los animales y las plantas; en definitiva, la vida escrita en fandangos.

Sin embargo, en los tiempos de bonanza que corren en los últimos años para el fandango con la realización de numerosos concursos y certámenes dedicados especificamente a este cante, pocos concursantes proceden desde la conocida localidad andevaleña. $Y$ no es una novedad. Desde que allá a mediados del siglo pasado los Hermanos Toronjo dieran a conocer a través de grabaciones y actuaciones en directo, no sólo el fandango, sino gran parte del patrimonio musical alosnero fuera de sus fronteras, se pueden contar con los dedos de una mano el número de cantaores originarios de Alosno que se han prodigado por los difíciles caminos artísticos.

Y es que para el alosnero el fandango va más allá del mundo del espectáculo. La mayoria de los aficionados de Alosno no han pisado en vida un escenario, ni saben de micrófonos, de focos o de públicos. Sin embargo son capaces de poner el vello de punta a cualquiera cuando una noche de Cruz de Mayo, una Vispera de San Juan o en alguna de las ocasiones que el extenso calendario festivo alosnero lo permite, lanzan su quejío al aire, desgranando con sus letras y su particular estilo lo más sentido y profundo, como una viva y real expresión de pureza de los cantes de este pueblo, y con unos matices musicales que sólo por estas tierras se le saben imprimir al fandango.

\section{Ramón Díaz Pérez}

Técnico de Cultura del Ayuntamiento de Alosno 